\title{
Familismo y cambio social. El caso de España
}

PEDRO SÁNAHZZ VEA* MARCOS BOTE DIAZ**

\section{Resumen}

El familismo de la sociedades está frecuentemente ligado a las limitaciones que presentan los Estados de Bienestar al hacer recaer sobre ellas un protagonismo excesivo. Referido a la sociedad española, los cambios sociales han sido importantes y rápidos, hasta el extremo que en algunos casos pueden transmitir la imagen de crisis familiar, pero sin embargo, la familia goza de una gran salud y sigue siendo de manera constante la institución más valorada por los españoles. No obstante, también quedan muchos ámbitos del cambio que están afectando a la solidaridad familiar y que presentan nuevos retos a la familia.

Palabras clave: Familismo. Cambio social. Estado del bienestar. Igualdad de género. Solidaridad familiar. Valoración del matrimonio. Ciclos familiares.

\section{Introducción}

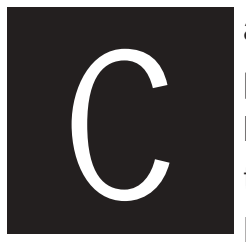
ada vez es mayor la preocupación dentro de la sociología por ver las implicaciones entre la familia, los estados de bienestar y las políticas sociales, en la medida que las políticas sociales interactúan con el funcionamiento actual de la familia. Sobre este asunto se han producido algunos libros importantes en los últimos años (v.gr: CARLIN G y DUNCAN 2.002). En un muy interesante trabajo (NALDINI, 2.003) se analiza el modelo de de

\footnotetext{
* Catedrático de Sociología. Universidad de M urcia, España.

** Profesor of Sociology U niversidad de Surrey, UK.
} 
microsolidaridad familiar en España e Italia, lo cual es muy interesante para conocer las relaciones entre familia-mercado-Estado.

En la Europa del Sur ha predominado un modelo de solidaridad familiar y de parentela (family/kinship solidarity model) con sólidos lazosfamiliaresy de parentesco, una mayor institucionalización del matrimonio, unas bajas tasas de divorcio y de cohabitación así como pocos nacimientos extraconyugales (NALDINI, 0.C: 25). Por otra parte, las obligaciones familiares se han extendido frecuentemente a miembros de la familia extensa de ambos cónyuges y sus parentelas (0.c: 25 y 74-77).

La protección social en el régimen mediterráneo sigue apoyándose sobre todo en la familia como productora y distribuidora de bienestar. El concurso de las mujeres en la provisión de cuidados no remunerados, principalmente para mayores y niños, ha sido decisivo en el mantenimiento de una sólida cohesión social en los países de la U nión Europea meridional.

Los poderes públicos han dado tradicionalmente, por descontado, la existencia de una fuerte obligación moral entre los miembros familiares, lo cual se ve reflejado en como los países latinos familistas han hecho un esfuerzo de gasto público mucho menor respecto ala familia que en los países más desfamilizados de la Europa del Norte. Así, la familia ha sido el principal canalizador y amortiguador de las carencias estatales en las políticas económicas y sociales en el régimen mediterráneo del bienestar, al haberse asumido que una parte importante de las actividades de bienestar y satisfacción vital de los ciudadanos serían cubiertos por la familia, con o sin ayudas públicas. Complementando, la acción de la familia a los servicios ofertad os por las organizaciones privadas son y sin ánimo de lucro.

En algunas sociedades, principalmente las anglosajonas, la familia nuclear empieza a ser una rareza, tal como han puesto de relieve acreditados especialistas (v.gr: CARLING y DUNCAN 2.002). Téngase en cuenta, por ejemplo, que los hogares estadounidenses compuestos por un matrimonio 
y sus hijos pasaron de un $45 \%$ a principios de 1.970 a ser menos de un $1 /$ 4 a principios del siglo XXI (CARLING y DUNCAN o.C: 52 ).

En las sociedades mediterráneas, los cambios en las nuevas formas familiares han sido también notables, pero en modo alguno son comparables a las de otros países (SÁN CHEZ VERA 2.003: 160-162). En los regímenes anglosajón y nórdico las familias monoparentales son ya la cuarta parte del total de familias con algún hijo menor de 18 años. En países como España e Italia, sin embargo, la proporción no llega a una de cada 10. Las implicaciones teóricas del modelo mediterráneo del régimen de bienestar, debería considerar no sólo las relaciones entre familia, mercado laboral y estado, sino que también debe considerar los modos de funcionamiento familiar y las relaciones familiares. 0 tra consideración importante es que en los análisis del estado del bienestar, desde la perspectiva del género, deben prestar atención a los recursos de los miembros de la familia y de la parentela en las "estrategias familiares" y en las repercusiones intergeneracionales.

Por estas latitudes del sur de Europa, la última generación de amas de casa ha duplicado su papel de madres, primero cuidando a sus propios hijos y después a sus nietos (IGLESIAS DE USSEL, 1.998). Sin embargo, la actual generación de madrestrabajadoras, no parece que vaya a reproducir losmismos roles, así en países como España e Italia, el fenómeno del doble sueldo (trabajan ambos cónyuges) está cada vez más extendido. Así, volviendo a la importancia que cada vez más van a tener los modos de funcionamiento familiar, lo que antes era un "asunto de mujeres" en el ámbito privado familiar se convierte, por tanto en un problema social que concierne al conjunto de la sociedad y que debe de ser solventado desde una óptica de conjunto y no meramente individualizadora al modo "anglosajón".

Referido a la evolución reciente de la población europea, distintos especialistas, han puesto de relieve como se ha reducido notablemente el tamaño objetivo de la red familiar (v.gr: PÉREZ DÍAZ, 2003; PÉREZ O RTIZ, 1.996; RODRÍGUEZ, 1.994; VIZCAINO, 2.000; WALACE, 2.000). Esta 
reducción de la red de parentesco afecta de manera desigual a las generaciones, puesa modo de ejemplo, mientras que la generación actual de adultos mayores, tiene una red de familiares directos relativamente alta, no puede decirse lo mismo de las nuevas generaciones (PÉREZ DÍAZ, 2003:62). Esta circunstancia puede afectar favorablemente a las generaciones de jóvenes que pueden tener el apoyo continuado de sus padres y abuelos, pero que genera manifiestas incertidumbres sobre la continuidad de la misma, tal como hemos puesto de relieve en distintos lugares (v.gr: SÁNCHEZ VERA, 2.003 y 2.007).

Desde la perspectiva familiar son frecuentes las reflexiones sobre el debilitamiento de la red familiar como ámbito de ejercicio de la solidaridad entre las generaciones, entre estos analistas se encuentra Francis Fukuyama, el cual aborda la familia moderna desestructurada como uno de losámbitos de "la gran ruptura" (FU KUYAM A, 2.000) y su incidencia en distintosámbitos de la vida social. El fenómeno de la longevidad y de las trayectorias familiares diversas crearán un cierto desamparo. Sobre este particular -y aunque muy centrado en la sociedad americana- señala lo siguiente (o.c: 160): “La persona anciana de principios del siglo XXI, pongamos por caso una mujer perteneciente al baby boom ya envejecida, divorciada dos o tres veces, vivirá sola sus últimos años en una casa 0 un piso y recibirá de vez en cuando la visita de un hijo (o hija) ya jubilado y que intenta sobrellevar el deterioro de su propia salud. Su conexión con estos parientes será débil debido a que la larga y azarosa vida personal que llevó de joven (los distintos matrimonios y parejas sexuales, los hogares separados y los conflictos respecto a la división de los bienes comunes y la custodia de los hijos) habrá dejado a sus descendientes una relación sentimental pero algo desapegada, que tendrá que competir con las exigencias de la distancia física y de actividades más agradables que los deberes familiares".

Es verdad que las reflexiones sobre la pérdida de influencia de la familia extensa y la crisis de la familia como institución en las sociedades post-industriales, es un asunto relativamente recurrente en los análisis sociológicos actuales. En cualquier caso, la caída de la natalidad y la consiguiente 
reducción del tamaño de la familia, no tiene porqué traducirse en el debilitamiento de la solidaridad relacional de las redes de parentesco. Un fenómeno ligado a esto ha sido la tendencia a la separación convivencial entre las generaciones. Sin embargo, no hay que perder de vista la elevada valoración que la familia sigue teniendo en determinados países, y que tal como señalan algunos de los grandes especialistas en Sociología de la Vejez (v.gr: BENGTSO N , 1.986; STREIB y BECK, 1.980), no hay que perder de vista el hecho de que el aumento en la esperanza de vida incrementa las posibilidades de coexistencia y tanto de interacción de tres generaciones en el ámbito familiar. A este hecho de naturaleza demográfica, vienen a decir alguno de los referidos autores, que se ha exagerado con frecuencia sobre la desaparición de la familia extensa en las sociedades industrializadas, pues aunque sea cierto el hecho de la mayor distancia física que caracteriza a los medios urbanos-incluso esto ha sido cuestionado también por algunos autores (TRO LL, L. (1.971)-, sin embargo las relaciones entre los miembros de la familia extensa sigue siendo muy importante en la mediada que se intercambian afecto, ayuda y servicios, y sobre todo, -tal como señala un especialista en la materia (WARD, 1.984)-, los sujetos siguen otorgando una gran importancia a sus relaciones familiares. 0 tros especialitas se han referido a la emergencia de la denominada "intimidad a distancia" esto es, la propiciada por las tecnologías: teléfono celular, internet, etccomo una nueva forma de revitalización de las relaciones familiares (RO SEN MAYR, 1.963), en opinión de alguno de estos especialistas este nuevo modelo creciente de solidaridad familiar, implica una elevada frecuencia de interacción y solidaridad. Referido al caso de España, M eil (2.000: 67) ha puesto de relieve como el principio de separación residencial entre las generaciones, no ha implicado un debilitamiento de losintercambios monetarios y/o de los servicios de apoyo mutuo entre las generaciones.

En cualquier caso, y tal como hemos señalado en otros lugares (SÁN CHEZ VERA 2.003 y SÁN CHEZ VERA, BOTE DÍAZ 2.007), la perspectiva generacional es básica a la hora de entender la percepción que las 
distintas generaciones tienen del matrimonio institucional (religioso y civil) del amor conyugal y de la familia. Así, esta perspectiva -la generacional-, siguiendo a Mannheim se sustenta en la verticalidad (en tanto que sucesión de generaciones a lo largo del tiempo) y en la horizontalidad (en tanto que coexistencia de generaciones distintas en un momento dado de tiempo). Así no es de extrañar que un mismo acontecimiento sea percibido de manera diferente en función de edad del sujeto en tanto que producto-resultado de los acontecimientos históricos y sistemas de valores que les ha tocado vivir (SÁN CHEZ DE LA YN CERA, 1.993). Así, los cambios acaecidos en la familia española y las diferentes actitudes generacionales hacia los mismos, son producto de una larga dictadura: la franquista (1.939-1.975) que impuso durante tiempo el modelo nacional-católico de familia (v.gr: FERRÁNDIZ, VERDÚ 2.004). No es de extrañar, que dichos cambios sean desigualmente percibidos, siendo y manifestándose, las generaciones más añosas como más próximas a un modelo tradicional de familia, a diferencia de las generaciones de la transición política (1.970-1.981) y posteriores, que se muestran mucho más permisivas con las nuevas formas de convivencia y de familia, tal como han puesto de relieves muy variados especialistas en la materia (v.gr: ALBERDI 1.999; DE M IGUEL 1.998; DE USSEL 1.998; DÍAZ NICO LÁS 1.997; FLAQU ER, SO LER 1.990; MEIL 2.000).

Dentro de los cambios acaecidos en la familia española de mayor relevancia y visibilidad ha sido el nuevo rol de la mujer. Este hecho ha sido central en una sociedad altamente sexista, donde el rol de la mujer quedaba relegado fundamentalmente al ámbito doméstico y a las relaciones de dependencia respecto al varón (ALBERDI 1.996). A partir de finales de los sesenta las cosas fueron cambiando, pero es con la Transición Política (iniciada básicamente tras la muerte del dictador) y sobre todo a partir de la Constitución de 1.981, cuando la presencia de la mujer es enorme en todos los ámbitos de la vida pública española. En opinión de algunos ha sido 
el asunto más trascendente acaecido en los 30 años de democracia últimos en España (v.gr: CABALLÉ, 2.006).

\section{Importancia de la familia en españa}

Pese a la importancia y alcance de los cambios sociales que han transformado profundamente la sociedad española desde la transición política tras la muerte del dictador Francisco Franco acaecida en noviembre del año 1.975 -, sorprende la vitalidad y la elevada valoración que sigue gozando la institución familiar a pesar de que se hayan disparado las cifras de divorcios y que el proceso de modernización y de secularización de la sociedad española ha entrado en todos los órdenes.

No es de extrañar esto en un país que no ha conformado aún un Estado del Bienestar -al menos al nivel de los países de su entorno Europeoni ha tenido tampoco una auténtica política de familia, a pesar de una la retórica familista con la que se venía adornando el régimen del general Franco (1.939-1.975) por influjo de la muy influyente Iglesia Católica. La elevada valoración que entre los españoles goza la institución familiar ha sido casi una constante en los estudios sociológicos, incluso entre las generaciones más jóvenes. Así desde la transición política hasta la actualidad, la familia ha venido aparecido como una de las instituciones más amables de la sociedad española, lo que se observa de manera constante a lo largo de los barómetros del Centro de Investigaciones Sociológicas de España (CIS). La familia se muestra como el aspecto vital mejor valorado, por encima de amigos, política, religión, bienestar económico o trabajo (CIS, 1987). El grado de satisfacción con la vida familiar también es elevado: en losúltimos 15 años, el $90 \%$ de los españoles han declarado mostrarse muy o bastante satisfecho con su vida familiar (CIS, 1994, 2.000).

Durante generaciones, y aún hoy, es la familia la que ha venido actuando de verdadero Ministerio de Asuntos Sociales (la mujer más 
exactamente) y resolviendo problemas de todo orden, que van desde el cuidado a los enfermos, la atención a los adultos mayores, la solidaridad con los miembros que quedan en paro, con los drogodependientes, los discapacitados, y así, un largo etc., que afecta a las ayudas de todo orden y tipo a los hijos, y muy particularmente a las hijas y nueras, en sus procesos de incorporación -de la mujer en general- al mercado de trabajo y que ha permitido, modernizar la sociedad española.

El sistema jurídico que regula las relaciones familiares ha sufrido en España desde la transición política a la actualidad una turbulencia inusitada que le ha dado un nuevo marco legal en los derechos que la regulan (SÁN CHEZ VERA, 1.994), siendo la Constitución de 1.981 el punto de partida de toda una cadena cambios legislativos. Véanse a modo de ejemplo, algunos de estos cambios legislativos:

- Constitución (1.978).

- Despenalización de la anticoncepción (1.978).

- Despenalización de los delitos de "Adulterio" y "Amancebamiento" (1.980).

- Ley de Divorcio (1.981).

- Supresión de las diferencias entre hijos "Legítimos" e "Ilegítimos",

"Matrimoniales" y "No Matrimoniales" (1.981).

- Modificación de la legislación sobre "Violación", "Abusos Deshonestos", "Estupro" (Supresión en todos los casos de los requisitos de: "doncellez" y "acreditada honestidad") (1.981).

- Modificación de la subordinación de la mujer al marido, pasando a las relaciones de igualdad (1.981).

- Ley de "Patria Potestas". Ley del Régimen Económico del Matrimonio.

Ley de Derechos y Deberes de los Cónyuges (1.981).

- Despenalización de la esterilización voluntaria (1.983).

- Despenalización parcial del aborto (1.985).

- Ley de Maltratos y Violencia Doméstica (2.002 y 2.005).

- Ley de "divorcio expres" (2.004). 
- Ley de Matrimonios Homosexuales (2.005)

- Ley de Dependencia (2.006).

- Ley de Igualdad de Género (2.007).

- Ley de ayudas económicas por natalidad (2.007).

Todos estos cambios lejos de debilitar, han revitalizado a la institución familiar, la cual, y a pesar del crecimiento en el número de separaciones y divorcios, tal como hemosseñalado, sigue siendo la institución más valorada por los españoles. Dejando al margen los cambios demográficos y políticos, lo primero a destacar de los resultados de los estudios que tienen por objeto la familia es la importancia que los españoles atribuyen a la misma. Sobre el familismo de la sociedad española se han pronunciado distintos especialistas en la materia (IGLESIAS DE USSEL, 1998; MEIL, 2000; MOREN O, 2002), siendo importantes las redes familiares en la solidaridad y en la reciprocidad, así como en la articulación de las relaciones sociales (SÁN CHEZ VERA, 2003).

Sobre el protagonismo de la familia y en particular sobre el mayor papel cuidador de la familia de clase baja española, un especialista en la materia dice lo siguiente: "A pesar de los cambios recientes a finales del siglo XX, la familia sigue siendo la primera institución de servicios sociales en la sociedad española. Por supuesto no todas las familias son iguales. Es un dato empírico que las familias de clase baja son más ayudadoras que las de clases altas. Este hecho tiene varias lecturas: a) las familias pobres tienden a ser más ayudadoras porque tienen más situaciones de precariedad entre sus miembros; b) a eso contribuye el que además son más extensas, tienen más miembros en posibles situaciones de precariedad, y menos ingresos per capita; c) quizás es que las familias de clases más bajas sean más generosas; d) es posible también que sean más pobres precisamente porque son mas altruistas. La realidad es una combinación de estas cuatro hipótesis" (DEMIGUEL, 1.998: 416-417).

Esta satisfacción con la vida familiar de los españoles, se desprende, asimismo, de la preferencia puesta de manifiesto en diversos estudios por 
disfrutar el tiempo libre, antes que solo, con la familia, en compañía de amigoso en otras situaciones diversas (CIS, 1992). Si bien esto ocurre también en otros países, es evidente que en España existe un perfil de especificidad que distingue la concepción de la familia de la de otros países de nuestro entorno (REHER, 1996). U na importante autoridad en la sociología como (MOYA, 1972: 93) señalaba:

dentro de la sociedad tradicional española resulta patente la condición sagrada del orden familiar. Frente al exterior - y frente a todo eventual conflicto interno- se encuentra rigurosamente protegido por todo un sistema de tabúes culturales, cuya explosión puede obligar, como última instancia, al crimen de sangre. La vieja ética castellana del honor no es sino un código familiar en el que toda otra imagen de lo sagrado se subordina a esa singular concepción del orden familiar.

Sin duda, aunque este escrito es de la década de los 70 y analiza una sociedad diferente a la actual, buena parte de los códigos señalados siguen vigentes.

Si la familia goza de una amplia valoración social, no cuenta con menos respaldo, en cuanto a percepción, el matrimonio. En una de las importantes encuestas so bre la materia (CIS 1992), las tres cuartas partes de los españoles preferían vivir casados sobre el resto de opciones: vivir solos, mantener una relación de pareja en domicilios separados, vivir con su pareja antes del matrimonio o sin proyecto matrimonial, o compartir la vivienda con amigos. No resulta por tanto contradictorio que en la misma proporción se considere que el matrimonio no está pasado de moda (CIS, 1987, 1992, 1994). En estudios más recientes (CIS 1997), tan sólo un 16\% de los españoles afirma que el matrimonio es una institución pasada de moda. Sobre este extremo Tabla № 1-, la evolución en los estudios del CIS es la siguiente: 
Tabla 1. Respuestas a la pregunta “ ¿Es el matrimonio una institución pasada de moda?" Valores en porcentajes. España, 1981-1999

\begin{tabular}{|c|c|c|c|c|c|c|c|c|}
\hline Año & $\begin{array}{c}1981 \\
(1296)\end{array}$ & $\begin{array}{c}1987 \\
(1698)\end{array}$ & $\begin{array}{c}1991 \\
(1990)\end{array}$ & $\begin{array}{c}1992 \\
(2001)\end{array}$ & $\begin{array}{l}1994 \\
\text { (CIS) } \\
(2113)\end{array}$ & $\begin{array}{l}1994 \\
\text { (EEV) }\end{array}$ & $\begin{array}{l}1995 \\
(2201)\end{array}$ & $\begin{array}{r}1999 \\
(2376)\end{array}$ \\
\hline De Acuerdo & 23 & 21 & 13 & 15 & 12 & 14 & 16 & 16 \\
\hline En Desacuerdo & 071 & 73 & 82 & 74 & 85 & 82 & 80 & 75 \\
\hline $\mathrm{NS} / \mathrm{NC}$ & 6 & 6 & 5 & 11 & 3 & 4 & 4 & 9 \\
\hline
\end{tabular}

Tal como se puede apreciar en la Tabla № 1, en los estudios del CIS la valoración del matrimonio como institución ha ido ganando adeptos: se ha pasado de una situación en la que casi uno de cada cuatro españoles afirmaba que el matrimonio era una institución pasada de moda a unos valores actuales en los que tan sólo un 16\% afirma esta sentencia, si bien cabe señalar que en años anteriores $(1992,1994,1995)$ los porcentajes de acuerdo han sido aún más bajos que en 1999, como ocurrió sobre todo a principios y mediados de la década pasada. En cuanto a los valores de 1999, señalemos que apenas existen diferencias por género, aunque existen diferencias importantes por edad -conforme aumenta la edad, más personas señalan su desacuerdo con la obsolescencia del matrimonio-. El estado civil también introduce importantes variaciones, hasta el punto de que el porcentaje de personas que indican su acuerdo con la afirmación del matrimonio como institución del pasado es el triple entre los separados/divorciadosque entre los casados. Los viudos también presentan porcentajes de acuerdo con la afirmación bajos, siendo, sin embargo, elevado el de los solteros (CIS, 1997).

Son las variables ideológicas las que introducen las diferencias más significativas. De este modo, los ateos o no religiosos presentan porcentajes más elevados de duda sobre la actualidad del matrimonio que los religiosos, los de izquierda frente a los de derecha, los potenciales votantes de Izquierda U nida o de nacionalistas de izquierda frente a los del Partido Popular o el 
PSO E y, por último, los definidos como postmaterialistas frente a los materialistas (CIS, 1997).

Tal como han puesto de relieve distintos estudios y la propia Encuesta Europea de Valores (EVS), España se encuentra entre los países que más importancia asignan al matrimonio, por lo que podríamos concluir que la institución del matrimonio cuenta con un sólido apoyo social desde prácticamente todas las capas de la sociedad, no siendo una condición anclada en la tradición "y que no entra en conflicto con el postmaterialismo ni la modernidad" (VALDIVIA, 2000: 113). Sin embargo, algunos creen que la sociedad tenderá en el futuro a darle menor consideración, como sucederá también con la familia (CRUZ CANTERO, 1994: 19).

Para la opinión pública española, todavía existe una estrecha relación entre procreación y matrimonio. En los estudios realizados, la mayoría de los españoles piensa que los hijos son la razón principal para tomar la decisión de casarse, y que quienes quieran tenerlos deberían casarse. No obstante, una proporción superior de encuestados opina que tener hijos no es la razón principal del matrimonio en la actualidad (CIS, 1994).

Las condiciones que se valoran como más importantes para el éxito del matrimonio (Tabla № 2) son las orientadas a la comunicación y el respeto en la pareja: la fidelidad, el mutuo aprecio y respeto, la comprensión y la tolerancia, el discutir los problemas, las relaciones sexuales, hablar sobre intereses comunes y pasar todo el tiempo que sea posible juntos. El tener hijos se presenta como un aspecto también de gran importancia para lograr el éxito en el matrimonio, aunque las estadísticas demuestren que los matrimonios sin hijos no se divorcian más que aquéllos que tienen sólo un hijo (RUIZ BECERRIL, 1999). 
Tabla 2. Condiciones para el éxito del matrimonio según resultados de encuestas de diferentes años (porcentaje de españoles que considera "muy importante" o "bastante importante" los siguientes factores para el éxito del matrimonio). España, 1981-1999

\begin{tabular}{lccccc}
\hline Aspecto & $\begin{array}{c}1981 \\
(1296)\end{array}$ & $\begin{array}{c}1987 \\
(1698)\end{array}$ & $\begin{array}{c}1990(\mathrm{CIS}) \\
(2113)\end{array}$ & $\begin{array}{c}1990 \\
(\text { EVS })\end{array}$ & $\begin{array}{c}1999 \\
(2376)\end{array}$ \\
\hline Fidelidad & 95 & 96 & 96 & 98 & 98 \\
Mutuo aprecio y respeto & 96 & 97 & 97 & 98 & 98 \\
Comprensión y tolerancia & 95 & 96 & 95 & 97 & 97 \\
Tener hijos* & 95 & 85 & 80 & 95 & 93 \\
Discutir los problemas & - & - & - & - & 94 \\
Relación sexual feliz & 90 & 92 & 90 & 95 & 94 \\
Hablar sobre intereses comunes & - & 89 & 85 & - & 90 \\
Pasar juntos todo el tiempo que & - & - & - & - & 90 \\
sea posible & & & & & \\
Compartir tareas domésticas & 61 & 65 & 64 & 75 & 78 \\
Ingresos adecuados & 85 & 84 & 90 & 87 & 83 \\
Vivir independientemente de & 70 & 62 & 70 & 69 & 70 \\
la familia política & & & & & \\
Compartir mismas creencias & 66 & 55 & 54 & 58 & 50 \\
religiosas & & & & & \\
Buenas condiciones de vivienda & 79 & 72 & 76 & 87 & 84 \\
Pertenecer al mismo medio social & 69 & 55 & 63 & 61 & 56 \\
Tener los mismos orígenes étnicos & - & - & - & - & 40 \\
Acuerdo en cuestiones políticas & 50 & 37 & 35 & 34 & 34 \\
Que la mujer trabaje fuera de casa & - & - & 43 & - & - \\
\hline
\end{tabular}

"En los estudios del CIS, el factor que aparece en este apartado es “Tener hijos", mientras que en los estudios del EVS aparece enunciado simplemente como "Los hijos". Entre paréntesis, número de estudio.

Fuente: Elaboración propia sobre datos de Barómetros de Opinión (CIS) y Encuesta Europea de Valores. (EVS). 
Destacan como cambios a reseñar, en primer lugar, la creciente importancia atribuida a la ejecución compartida de las tareas domésticas: si en 1981 poco más del $50 \%$ de la población consideraba muy o bastante importante este factor, en 1999 casi cuatro de cada diez españoles eran de esta opinión; han decrecido, por otro lado, losfactores socio-ideológicos: la importancia atribuida al medio social de procedencia o las creencias religiosas y políticas, aunque la mayor parte de los consultados afirma que ambos miembros de la pareja tienen idénticos puntos de vista respecto a losmismos (CIS, 1994). Del mismo modo, el compartir un mismo origen étnico aparece como un factor al que se atribuye escasa importancia en 1999 (40\%).

Por otro lado, a pesar del elevado familismo de la sociedad española, el grado de tolerancia de los españoles ante las parejas que deciden convivir sin estar casadas es elevado y creciente, y la mayoría aprueba la cohabitación con o sin fines matrimoniales. En el marco de los cambios en las formas de vida familiar que se han originado en los últimos años, el aumento del número de parejas que viven juntas sin estar casadas se considera más beneficioso que perjudicial. En cualquier caso, incluso los entrevistados que se manifiestan partidarios del matrimonio civil o canónico consideran que el hecho de vivir en pareja sin casarse es una decisión personal plenamente aceptable (CIS, 1987, 1992a).

La opinión pública española reconoce que las parejas no casadas deberían tener los mismos derechos que las casadas. Al analizar la proyección de las actitudes ante la posibilidad de tener como vecinos a "parejas de hecho", se observa que esta situación hipotética no supond ría incomodidad entre la mayoría, como tampoco sería un problema la hipótesis de que un hijo/a conviviera con otra persona sin contraer matrimonio. Esta tolerancia, aun siendo predominante en todos los casos, disminuye sensiblemente cuando se trata de la cohabitación entre personas del mismo sexo. Respecto a los derechos de estas parejas homosexuales, en el terreno abstracto se 
opina que deberían tener los mismos que las heterosexuales; sin embargo, cuando se desciende a lo concreto, la mayoría no se muestra de acuerdo con otorgarles la posibilidad de adoptar hijos, y la muestra se divide en proporciones muy similares a la hora de expresar su acuerdo o desacuerdo con el matrimonio entre personas del mismo sexo (CIS, 1997). De hecho, en 1999, el 84\% de los españoles afirmaba que "un niño necesita de un hogar con un padre y una madre para crecer felizmente (ELZO Y O RIZO, 2000: 122).

La distancia entre la opinión pública española y los comportamientos respecto a las nuevas formas de convivencia es importante. Entre los entrevistados casados, tan sólo el 7\% convivió con su cónyuge antes de contraer matrimonio; sin embargo, esta proporción se multiplica entre los más jóvenes y entre quienes tienen estudios superiores (CIS, 1995) y algo más de la mitad de los consultados tiene algún familiar o amigo que está conviviendo con otra persona sin estar casado (CIS, 1994).

La cohabitación se muestra, pues, como una realidad establecida en el paisaje social. No obstante, es sabida la dificultad existente en España para conocer con exactitud la cifra de parejas cohabitantes. Los padrones municipales de habitantes no tienen todavía resuelta la dificultad de identificar a los cohabitantes, por lo que la mayor parte de los estudios que se han realizado sobre la cohabitación han recurrido a técnicas de investigación cualitativas (CIS, 1987; CEA Y VALLES, 1994).

Por otra parte, se observa un conflicto de valoresal analizar las opiniones sobre algunos cambios familiares. A pesar de la elevada aceptación del divorcio o la separación matrimonial como solución a determinados conflictos conyugales (CIS, 1997), la mayor parte de los entrevistados califica como perjudicial el aumento del número de divorcios que se ha observado en los últimos años (CIS, 1992a). Del mismo modo, a pesar de que la mayoría se muestra contraria a la idea de que un solo progenitor pueda criar a un hijo 
tan bien como el padre y la madre juntos, opinan que la existencia de hijos no debe limitar la libertad de los padres para tomar la decisión de separarse. Tan sólo se muestran algo reacias a la separación matrimonial las personas adultas (45 y más años de edad) con escaso nivel de instrucción (CIS, 1997).

\section{Cambios demográficos en el ciclo vital de la familia española}

El panorama actual sobre la familia vive una sonora agitación. A los numerosos cambios vividos por esta institución se le ha prestado atención desde diferentes ópticas, como la dimensión política (IGLESIAS DE USSEL, 1998) o la dimensión relacional del matrimonio, en relación directa con otros estudios de ámbito europeo (BECK Y BECK, 2001; ALBERO NI, 1992). Debido a estas continuas transformaciones, nunca ha tenido esta institución social tantas modalidades como en el presente: familia reconstruida, familia recompuesta, monoparental, homoparental, "engendrada artificialmente", etc. A la vista de lo expuesto, puede afirmarse que la familia occidental parece sumida en una entropía ingobernable, que la convierte en víctima y verdugo de una sociedad donde se han perdido referentes culturales únicos y coercitivos. La sociología no permanece ajena a estas transformaciones. Si antes se decía que el amor era un azar y el matrimonio era una certidumbre, ahora "se han invertido las tornas y sólo el amor es una certidumbre, al menos como proyecto, mientras que el matrimonio es una situación cada vez menos definitiva y más reversible. Es el reino de la incertidumbre" (ALBERDI, 1996).

En España, tras la transición demográfica y la aprobación de la ley del divorcio en el año 1.981, se experimentó un intenso debate sobre la influencia del cambio social en los roles del varón y la mujer en el seno de la familia. El cambio social afectó claramente a la estructura familiar, descendiendo la fecundidad y la nupcialidad. En aquella época, la caída fue 
intensa, lo que suscitó una gran agitación académica y social (CONDE, 1982). A grandes rasgos, cabe resumir del modo siguiente los cambios básicos experimentados por la familia en España a lo largo de losúltimosaños (DEL CAMPO, 1982):

a) Ha habido un cambio en la duración absoluta del ciclo vital familiar - desde que se constituye hasta que se extingue- como consecuencia del generalizado alargamiento de la vida, así como una transformación en la duración de cada una de sus etapas. Especialmente destaca la transformación que ha experimentado la fase de nido vacío, que ha aumentado notablemente su duración.

b) Ha cambiado significativamente el calendario de la nupcialidad.

c) Las pautas de reproducción y fecundidad han experimentado, asimismo, variaciones sustanciales: menor número de hijos, acumulación de losmismosal principio del matrimonio, conocimiento y uso creciente de anticonceptivos.

d) Las relaciones internas de la familia (marido/mujer, padres/hijos, familia nuclear/familia extensa) han ido progresivamente equiparándose a las predominantes en los países industrializad os del área occidental. e) La progresiva integración laboral de la mujer ha tenido toda una serie de consecuencias en la remodelación de la dinámica familiar. f) Las pautas de conflicto y desintegración familiar han experimentado variaciones sustanciales, tanto en sentido cuantitativo como, sobre todo, cualitativo. De hecho, en una sociedad industrial, secularizada, el conflicto familiar no es que sea forzosamente más frecuente, sino que su explicitación y reconocimiento están menosinhibidos, dando paso a su institucionalización (en vez de a su ocultación y represión). Esto se manifiesta, por un lado, en el creciente número de divorcios, aunque también, de forma más dramática, en la visibilidad social de la violencia de género. 
El cambio más significativo (y el que más atañe a nuestro objeto de estudio) registrado por la familia española durante el siglo pasado es sin duda el de las profundas variaciones aparecidas en la estructura y dinámica del ciclo vital familiar (Tabla $\mathrm{N}$ o 3). Sencillamente, desde que se crea hasta que desaparece, la unidad familiar atraviesa una serie de etapas de significado y trascendencia muy distintos.

Un primer período del ciclo vital (que en la literatura sociológica suele ser designado como nido sin usar) abarca desde el matrimonio hasta el nacimiento del primer hijo. El segundo periodo coincide con el intervalo fecundo. La tercera etapa comprende desde el momento en que se va el primer hijo hasta que lo hace el último; se trata de un periodo en el que la familia puede ser percibida como "plataforma de colocación". Viene después el periodo de nido vacío (cuando el núcleo familiar vuelve a quedar reducido a los dos cónyuges). Por último, se alcanza la etapa final con la defunción de uno de los cónyugesy, posteriormente, la del supérstite (DEL CAM PO , 1995).

Pues bien, como consecuencia de los profundos cambios demográficos, culturales y socioeconómicos acaecidos en España desde comienzos de siglo, se han producido importantes variaciones en la extensión y dinámica de cada una de estas etapas básicas de ciclo vital de la familia española. U na de las transformaciones más reseñables estriba en la duración media del ciclo vital familiar, que en el 2001 era de 53,77 años frente a 27,8 en el año 1900. Esta radical ampliación de la duración de la familia es resultado no tanto de cambios en las edades en que se contrae matrimonio sino de los profundos cambios en la incidencia de la mortalidad y su correlativo impacto en la esperanza de vida de los individuos. Sencillamente, mientras que dicha esperanza media de vida era en 1900 de tan sólo 33,8 años para el hombre y de 37,7 para la mujer, en 1975 alcanza los 69,6 y los 75,1 respectivamente. Apenas en unas generaciones se ha duplicado ampliamente (DEL CAM PO, 1980; INE, 2004).

Como consecuencia de este alargamiento sustancial de la vida, la parte que corresponde en ella al ciclo familiar decrece y ello pese al impor- 
Tabla 3. Indicadores del Ciclo Vital de la Familia española en el siglo XX

\begin{tabular}{|c|c|c|c|}
\hline INDICADOR & 1900 & $1970-75$ & $1999-2003$ \\
\hline $\begin{array}{l}\text { 1. Diferencia de edad } \\
\text { marido-mujer al casarse }\end{array}$ & 1,90 & 1,90 & 2,02 \\
\hline $\begin{array}{l}\text { 2. Edad media de la } \\
\text { mujer al casarse }\end{array}$ & 24,60 & 23,70 & 28,39 \\
\hline $\begin{array}{l}\text { 3. Esperanza de vida } \\
\text { de la mujer al nacer }\end{array}$ & 35,70 & 75,10 & 82,16 \\
\hline $\begin{array}{l}\text { 4. Esperanza de vida del } \\
\text { hombre al nacer }\end{array}$ & 33,80 & 69,60 & 75,25 \\
\hline 5. Duración del ciclo vital & 27,80 & 45,10 & 53,77 \\
\hline $\begin{array}{l}\text { 6. Porcentaje de la duración } \\
\text { del ciclo vital sobre la vida } \\
\text { media de la mujer }\end{array}$ & 77,90 & 60,00 & 65,44 \\
\hline $\begin{array}{l}\text { 7. Porcentaje de la duración } \\
\text { del ciclo vital sobre la vida } \\
\text { media del hombre }\end{array}$ & 82,20 & 64,80 & 71,02 \\
\hline 8.Número medio de hijos & 4,71 & 2,50 & 1,30 \\
\hline $\begin{array}{l}\text { 9. Numero de miembros } \\
\text { de la familia }\end{array}$ & 3,87 & 3,84 & 3,12 \\
\hline $\begin{array}{l}\text { 10. Etapa de nido sin usar } \\
\text { (hasta el primer nacimiento) }\end{array}$ & 1,90 & 1,40 & 2,40 \\
\hline $\begin{array}{l}\text { 11. Duración en años del } \\
\text { intervalo fecundo }\end{array}$ & 12,70 & 7,50 & $3,90 *$ \\
\hline $\begin{array}{l}\text { 12. Número medio de años } \\
\text { entre nacimientos }\end{array}$ & 2,70 & 3,00 & $3,90 *$ \\
\hline $\begin{array}{l}\text { 13. Porcentaje de la duración } \\
\text { del intervalo fecundo sobre } \\
\text { el ciclo vital }\end{array}$ & 45,70 & 16,60 & 7,25 \\
\hline 14. Nido Vacío & - & 11,70 & 13,2 \\
\hline $\begin{array}{l}\text { 15. Porcentaje de la duración } \\
\text { del nido vacío sobre el ciclo vital }\end{array}$ & - & 25,90 & 24,55 \\
\hline $\begin{array}{l}\text { 16. Duración de la viudez } \\
\text { de la mujer }\end{array}$ & 9,40 & 9,00 & 9,50 \\
\hline $\begin{array}{l}\text { 17. Duración de la viudez } \\
\text { del hombre }\end{array}$ & 1,60 & 2,20 & 2,30 \\
\hline $\begin{array}{l}\text { 18. Probabilidad de morir } \\
\text { primero el hombre (mujer: } 1 \text { ) }\end{array}$ & 1,60 & 2,70 & 4,70 \\
\hline
\end{tabular}

* En el caso de aquellas familias que cuentan con al menos dos hijos (el $27 \%$ del total de lasfamilias). Fuente: Elaboración propia. Para 1900 y 1970-75, (Del Campo, 1980); para datos actuales, (INE, Movimiento Natural de la Población 2003b, 2004c, 1999d). 
tante alargamiento de éste. En el año 1900, la duración del ciclo vital familiar representaba el 82,2 por 100 del total de la vida del hombre y el 77,9\% del total de la vida de la mujer. En el año 2003, supone el $71 \%$ y el $65,4 \%$ respectivamente. De aumentar la esperanza de vida, estos porcentajes podrían igualarse pese al retraso en el inicio del ciclo familiar.

Por otro lado, la etapa de nido sin usar se ha acercado a la del resto de países de nuestro entorno. Este período se ha ido alargando, entre otras cosas, debido a la voluntad de la mujer de retrasar la maternidad, supeditándola a la estabilidad laboral. Si en 1900 este período era de 1,9 años, en 2001 el valor es de 2,4 años.

O tros indicadores que conformaban el ciclo vital, al menosdurante tres cuartas partes del pasado siglo, han perdido relevancia. Un claro ejemplo es lo que se llama el período fecundo, es decir, el número de años de la etapa fecunda que las mujeres invertían en tener el número medio de hijos. En la actualidad, con un número medio de hijos por mujer de 1,3 y un $46 \%$ de las mujeresentre 15 y 59 años que no tienen ningún hijo (Encuesta de Fecundidad 1999), este indicador no tiene mucho sentido, si bien puede señalarse que el período entre el nacimiento del primer y el segundo hijo (en el caso de las mujeres que han tenido al menos dos hijos, un 26,31\% según la encuesta de fecundidad) es de 3,9 años, muy por debajo de los 12,7 años que invertían las mujeres de 1900 para tener sus 4,71 hijos. Es decir, la duración del intervalo fecundo se ha reducido sensiblemente y se tiene muchos menos hijos, aumentando considerablemente el esparcimiento entre nacimientos. Tenemos así que, mientras a principios de siglo la etapa fecunda dentro del ciclo vital familiar comprendía prácticamente la mitad de la duración de éste (exactamente el 45,7\%), en 1999 (año de la encuesta de fecundidad) este periodo es tan sólo del 7,25\%. Sin duda, estamos asistiendo al divorcio definitivo entre el matrimonio (familia) y la función de procreación.

La llamada etapa de nido vacío resulta difícil de integrar en el ciclo vital. En el caso de que se tenga sólo un hijo, esta etapa comenzaría a los 
59,8 años en el caso de la mujer y los 62 en el caso del varón. En cambio, si se tienen dos hijos, esta etapa comienza a los 63,7 años en el caso de la mujer y a los 65,9 en el del varón. Este periodo (inexistente a principios de siglo, cuando la etapa de "nido vacío" coincidía con la desaparición de la familia) alcanza una duración más que apreciable y que ha ido en aumento. En caso de que se tenga tan sólo un hijo, desde que éste se marcha hasta el fallecimiento de uno de los esposos transcurren 13,2 años, lo que supone una novedad total en la mesura de la familia. Si se tienen dos hijos, cuando éste último se va de casa, a los cónyuges les quedan 10,7 años de nido vacío. Es decir, las nuevas posibilidades que ofrece el envejecimiento son múltiples. Si en ocasiones esta etapa es vivida bajo la predominancia de un sentimiento de soledad (IM SERSO, 2002; IGLESIAS DE USSEL, 2001 a), no cabe duda de que debe apostarse por una actitud positiva y una vejez activa a la hora de enfrentarse al abandono del hogar de los hijos, aprovechando esta etapa de la vida para llevar a cabo proyectos que habían sido demorados en el tiempo. En el caso de que sea tan sólo uno de los progenitores el que alcance esta etapa, la opción de establecer una relación afectiva puede ser una perfecta iniciativa para emprender la última etapa del ciclo vital, con las ventajas que esto puede comportar para el estado anímico del sujeto mayor.

\section{Epilogo}

La familia en España ha tenido una serie de transformaciones relativamente rápidas y de amplio calado, que sin embargo no han alterado en profundidad el familismo de la sociedad española.

Las limitaciones y carencias que ancestralmente ha presentado el Estado de Bienestar de España, han dado un protagonismo importante a la institución familiar que ha llevado a que los lazos de solidaridad familiar hayan tenido que cubrir importantes lagunas no cubiertas por las 
administraciones públicas. El envejecimiento de la población y las necesidades derivadas del cuidado a los adultos mayores, la precariedad del empleo juvenil y la tardanza en la emancipación de losjóvenes o la escasez de políticas que hasta fechas recientes -sobre todo hasta la reciente entrada en juego de la Ley de Discapacidad-, son algunos ejemplos de las referidas carencias. Sin embargo, también deben ser tomados en consideración una serie de rasgos de carácter cultural que favorecen una cierta fidelidad familiar, y de otro una serie de cambios y transformaciones de la familia. En cualquier caso y referido a la atención a los adultos mayores, los estudios sociológicossiguen poniendo de relieve como el cuidado de los mayores es responsabilidad de la familia. Los últimos barómetros del CIS (v.gr: 2.004), el $86,8 \%$ de los encuestados consideraba que es un deber "principalmente de los hijos" asistir a sus padres mayores. El mismo porcentaje cree, sin embargo, que esto no exime al Estado y las administraciones públicas de su obligación de velar por el bienestar de los mayores.

Unas cierta imagen de crisis en la institución familiar es un hecho relativamente extendido, en la medida que en la sociedad tradicional, las actividades familiares quedaban en la privacidad y las imágenes negativas de esta no trascendían el ámbito doméstico, sin embargo, hoy es cada vez más frecuente la presentación de estadísticas de separaciones y divorcios, de malos tratosa mujeres, o cómo a través de los medios de comunicación son frecuentes estas imágenes perversas: abandonos, adulterios, incestos, y por supuesto violencia de género. A pesar de todo, la familia sigue apareciendo como un referente central en la vida social de los españoles.

Si hubiera que citar los dosasuntosque mayor grado de visibilidad han tenido en los últimos años (sobre todo en la última década) en España, dos habría que señalar.

Primero: la visibilidad de la violencia de género (enorme número de muertes de mujeres y de malos tratos) y la percepción de estos como un 
problema social de primer orden, sobre todo cuando las mujeres se han decido a denunciar abiertamente apoyadas por el Código Penal y la Ley de M altratos y Violencia D oméstica (2.002 y 2.005).

Segundo: la visibilidad de la homosexualidad, históricamente relegada y perseguida durante la dictadura (U GARTE PÉREZ, 2.008). El nivel de presencia de la homosexualidad en distintos ámbitos de la vida pública, y la tolerancia, mostrada por la sociedad española, han llevado a que esta sea percibida como un derecho.

U no y otro hecho: violencia de género y homosexualidad, en efecto, pueden haber contribuido a una cierta apariencia de crisis de la familia en España, pero nada más lejos de la realidad, la familia esta goza de una excelente salud y de un clima doméstico envidiable (MEIL, 2.006), que en opinión de distintos especialistas explica mayoritariamente el retraso en el calendario de la independencia de los hijos respecto del hogar familiar (MIRET, 2.007; PÉREZ-DÍAZ y RO DRÍGUEZ 2.007), y además sigue siendo la más valoradas de las instituciones (v.gr: MEIL 0.c: 11-43; Centro de Investigaciones Sociológicas: Estudios 2616/2005 y 2633/2.006).

De otra parte, un fenómeno en el que sin duda habrá que incidir aún más, es el de las diferencias de género en el ejercicio real de la solidaridad familiar. Referido en concreto al cuidado de los mayores adultos, según los estudios realizados sobre vejez y familia en España, son las familias las que en un 90 \% cuidan al anciano cuando está enfermo (MORENO, 2.000: 124-130). A este respecto y de manera muy gráfica, Iglesias de U ssel se refiere a la familia y en concreto la mujer, como "el verdadero M inisterio de Asuntos Sociales en España” (IGLESIAS DE U SSEL 1.998: 260). De manera igualmente gráfica y de forma más contundente, Luis M oreno se refiere al "rol cambiante de la supermujer" meridional" (MOREN O , 2.000: 124-130) para poner de relieve el esfuerzo que supone para la mujer la coexistencia del cambio de roles en el ámbito laboral y el mantenimiento de ciertas 
obligaciones familiares, sobre todo en lo concerniente a la atención a los mayores. Distintos estudios sociológicos recientes realizados por el Instituto de la Mujer, por el CIS, o por distintos investigadores, han puesto de relieve la pervivencia de una desigual distribución de tareas dentro del hogar (CRUZ CANTERO, 1.995, págs. 53-57). Un estudio de Tabula de 2.000 (DE M IGU EL 2.000) prestaba especial importancia a este aspecto, y afirmaba lo siguiente: "Esun hecho que la igualdad de los sexos respecto a la ejecución de tareas domésticas resulta bastante lejana".

Con todo, un buen número de estudios sociológicos, han destacado, de una parte, la tendencia progresiva de los varones a compartir las tareas domésticas, y por otra, la pervivencia de diferencias importantes de género en la distribución de obligaciones sobre dichas tareas (CRUZ CANTERO 1.995). Aunque, en lo referente al cuidado de mayores, como muy bien matiza Inés Alberdi, y con respecto al mayor número de varones que de mujeres -según la encuesta del CIS de 1.993- que declaran cuidar de un anciano con la ayuda de alguien más: "Cabe suponer que aquellos que les ayudan sean, en gran parte, esposas hijas o hermanas, con lo que se corroboraría que las mujeres son las que llevan en mayor medida la carga del cuidado de los ancianos. Y esta idea se refuerza porque, por el contrario, aquellos que dicen no tener ningún tipo de ayuda para atender a los mayores (42\% dicen que tienen que atender a un anciano) son, fundamentalmente, mujeres. Entre estos aumentan las personas con menor nivel cultural, las que viven en el medio rural, así como las que tienen más de tres hijos. Es decir, que en el cuidado de los ancianos encontramos en gran medida a las mujeres, ya que son muy numerosas las que llevan a cabo esa responsabilidad en solitario y, por otra parte, encontramos un gran número de hombres que comparten el cuidado de un anciano con alguna mujer que también cuidado de él (ALBERDI 1.999:343). 


\section{Familism and social change: the case of Spain}

\section{Abstract}

Within society, familism is often related to the limitations presented by the welfare state, forcing them to play an excessive role. Social changes in Spanish society have been significant and rapid, in some cases to the point of disseminating the idea of family crisis. Nonetheless, the family is in good health and continues to be the most valued institution in Spain. M eanwhile, there are many areas of change currently affecting family solidarity and presenting new challenges to the family.

Keywords: Familism. Social change. Welfare state. Gender equality. Family solidarity. Family cycles.

\section{Referencias}

ALBERDI, I. "Un amor para toda la vida", en Castaño, C. y Palacios, S. (eds.): Salud, dinero y amor. Cómo viven las mujeres españolas de hoy. Madrid: Alianza, 1996.

ALBERDI, I. La nueva familia española. Madrid. Santillana, 1999.

BECK, U.; BECK, E. El normal caos del amor. Barcelona: Paidós, 2001.

BENGTSO N V. L. "Sociological Perspectives in Aging, Families and the Future." In: M. Bergener, ed., Perspective on Aging: the 1986 Sandoz lectures in gerontology. Academic Press. New York., 1986.

CABALLÉ, A. Una breve historia de la misoginia. Lumen. Barcelona, 2006.

CARLING, A; DUNCAN. Analysing Families: morality and racionality in policy and practice. Londres, Routledge, 2002.

CEA, M. A. y VALLES, M. S. "Nuevos estilos de vida en relación con la vivienda: hogares unipersonales y parejas cohabitantes". Familia y Sociedad, 1/2, 91-110, 1994.

CIS. Evolución del Sistema de valores y proceso de secularización de da Sociedad Española. Estudio 1698, 1987.

. O piniones y actitudes 9. Población y Familia. Estudio 1990, 1992a.

. Evolución del sistema de valores (IV). Estudio 2001, 1992.

. O piniones y actitudes 20. Población y Familia. Estudio 2113, 1994. 
. Datos de opinión 3. Perfiles Actitudinales. Estudio 2203, 1997.

CONDE, R. Familia y cambio social en España. CIS. Madrid, 1982.

CRUZ CANTERO, P. "Percepción social de la familia en España". O piniones y Actitudes № 9. CIS. Madrid, 1995, págs. 53-57.

CRUZ CANTERO P., SANTIAGO GO RDILLO P. Juventud y entorno familiar. Madrid: Injuve, 1999.

DE M IGU EL, J.M . Estructura y cambio social en España. Alianza. Madrid, 1998. pp. 416-417.

DE MIGUEL, A. La sociedad española 1.995-2.000. Madrid. Ed. Complutense, 2000.

DEL CAM PO , S. Informe Sociológico sobre la familia española. M adrid: Ministerio de Cultura, 1980 y 1982.

DEL CAM PO, S. Familias: Sociología y Política. Madrid: Complutense, 1995.

DÍAZ NICO LÁS, J. "La estructura de los hogares españoles”, en Rafael Puyol (ed) Dinámica de la población española. Cambios demográficos en el último cuarto del siglo XX. Síntesis. Madrid, 1997. pp. 145-166.

ELZO, J.; O RIZO , F.A. Jóvenes Españoles 1.994. Fundación Santa M aría. Editorial S.M. Madrid, 1994.

FLAQ U ER, L.; SO LER, J. Permanencia y cambio en la familia española. Estudios y Encuestas № 18. CIS. Madrid, 1990.

FERRÁN DIZ, A.; VERDÚ, V. Noviazgo y matrimonio en la vida española 1.9742.004. Taurus. Madrid, 2004.

FU KUYAMA, F. La gran ruptura: naturaleza humana y reconstrucción del orden social. Ediciones B. Barcelona, 2000.

IGLESIAS DE U SSEL, J. La familia y el cambio político en España. Madrid: Tecnos, 1998.

INE. Encuesta Sociodemográfica. Madrid, 1991.

. Encuesta de Fecundidad. Madrid, 1999.

. Indicadores Sociales de España. Madrid, 1999.

IM SERSO. "Las personas mayores en España". Informe 2002. Madrid: M inisterio de Trabajo y Asunto Sociales, 2002.

M EIL, G. Imágenes de la solidaridad familiar. CIS. O piniones y Actitudes № 30. Madrid, 2000. 
M IRET GAM UNDI, P. "Pautas longitudinales de emancipación juvenil en España". En Anna Cabré (Dir.) La constitución familiar. Fundación BBVA. Bilbao, 2007. pp. 42-91.

MORENO, L. "La última red” de protección social. Ariel. Barcelona, 2000. pp. 124-130.

MOYA, C. "Familia e Ideología Política", en Las Ideologías en la España de Hoy (coloquio). M adrid: VV.AA. Seminarios y Ediciones, 1972.

NALDINI, M. The Family in the Mediterranean Welfare States. Londres: Frank Cass, 2003.

PÉREZ DÍAZ, J. La madurez de masas. Madrid: IM SERSO, 2003.

PÉREZ-DÍAZ, V.; Rodríguez, J.C. La generación de la transición entre el trabajo y la jubilación. La Caixa. Volumen 35, de la Colección Estudios Económicos, 2007.

PÉREZ O RTIZ, L. Las necesidades de las personas mayores (vejez, economía y sociedad). IMSERSO. M adrid, 1996.

REHER, D. La familia en España, pasado y presente. M adrid: Alianza, 1996.

RODRIGUEZ , J. A. Envejecimiento y familia. Siglo XXI. M adrid, 1994.

RO SEN M AYR, L.; KO EKEIS, E. "M arriage, family and friendships", en J. B. W illiamson, Aging and Society: an introduction to social gerontology. Holt: Rinehart y W inston. Nueva York, 1963. pp. 89 y ss.

RUIZ BECERRIL, D. Despues del divorcio: los efectos de la ruptura matrimonial en España. Madrid: CIS, 1999.

SÁNCHEZ VERA, P. “Consideraciones metodológicas sobre investigación de la familia en España”. Revista Internacional de Sociología. Tercera Época N o 6, pág 103-125. Instituto de Estudios Sociales Avanzados. Madrid. Consejo Superior de Investigaciones Científicas, 1994.

SÁN CHEZ VERA, P. "La Solidaridad intergeneracional”. En José Felix Tezanos (ed). Tendencias en Desvertebración Social y Política de la Solidaridad. Madrid: Editorial Sistema, 2003. pp. 153-190.

SÁN CHEZ VERA, P. “La participación como mecanismo de exclusión”. En Blázquez M arín (Ed). Los derechos de las personas mayores. Instituto de Derechos H umanos Bartolomé de las Casas. Ed. Dykinson. Madrid, 2007. pp. 71-100

SÁNCHEZ VERA, P.; Bote Díaz M. Los mayores y el amor (una perspectiva sociológica). Nau Llibres. Valencia, 2007.

SÁNCHEZ DE LA YNCERA, I. La obra de Karl Mannheim: una compilación actualizada de sus escritos más relevantes. REIS No 62. CIS. Madrid, 1993. pp. 245-2-53. 
STREIB, G.; Beck, R. "O Ider families: a decade review", en Journal of Mariage and the Family, 42, 1980. pp. 937-956.

TRO LL, L. "The family of later life: a decade review", en Journal of Mariage and the Family, 33, 1971. pp. 263-390.

U GARTE PÉREZ, J. (ed) U na discriminación universal (la homosexualidad bajo el franquismo y la Transición). Egales. Madrid, 2008.

VALDIVIA, C. "La Familia", en Elzo, J. y O rizo, F. A. (dirs.): España 2000, entre el localismo y la globalidad. Madrid: Fundación Santa M aría, 2000.

VIZCAINO M ARTÍ, J. Envejecimiento y atención social. Herder. Barcelona, 2000. WALACE, P. El seísmo demográfico. Alianza. Madrid, 2000.

WARD, R. A. The aging Experience. Harper; Row. Londres, 1984. pp. 218-219.

Recebido: 26/02/2008

Aceite final: 06/03/2008 